\title{
STRUCTURAL OPTIMIZATION OF LATHE MACHINE BED
}

\author{
SURESHA. D. B, DEVENDRA REDDY. M \& MURALI. C T \\ Assistant professor, Department of Mechanical Engineering, \\ Sri Venkateshwara college of Engineering, Bangalore, India
}

\begin{abstract}
In this paper, a machine bed is chosen for the entire investigation, for both static and dynamic burdens. At that point, examination is completed to decrease the heaviness of the machine bed, without falling apart its basic inflexibility and the precision of the machine apparatus, by including ribs at the appropriate areas. In this work, the 3D CAD display of the standard and the advanced outline has been made by utilizing business $3 D$ demonstrating programming, CATIA. The 3D FE demonstrate, has been created utilizing HYPERMESH. The investigations were completed, utilizing ANSYS and Design Optimization is finished with the assistance of Optistruct. The outcomes were appearing with the assistance of charts, to breakdown the impact of weight diminishment on the auxiliary uprightness, of the machine bed prior and then afterward the weight lessening and conclusions were drawn, about the improved plan.
\end{abstract}

KEYWORDS: Structural Integrity, Optimization \& Lathe Machine

Received: Aug 08, 2017; Accepted: Aug 29, 2017; Published: Sep 07, 2017; Paper Id.: IJMPERDOCT201715

\section{INTRODUCTION}

The machine bed plays a crucial role, in providing the strength and rigidity to a machine. It accommodates all the accessories and cutting tools, and other necessary equipment's for the running of the machine. It is subjected to various static and dynamic forces, during the operation. Its design is vital to the performance and accuracy of the machine tool.

As a supporting piece of a machine, the machine bed is for the most part utilized, for putting such essential segments as lead rail and headstock. In order to meet the high requirements of computer numerical control (CNC), for speed, accuracy, productivity, reliability and automation degree, and compared with ordinary lathes, CNC lathes are superior in static and dynamic stiffness, and vibration resistance. Because of the high multifaceted nature of machine beds, with respect to basic shape, it will be exceptionally hard to do the computations for its static/dynamic qualities, by methods for ordinary techniques. With the development of limited component hypothesis, and the advancement of PC system, it is a broadly utilized technique to play out a static/dynamic trademark examination, by building three-dimensional demonstrating and performing limited component investigation, with the product instrument radius. But, this method is easy to lead to data loss and hence, needs plenty of time for model repairing. We know that, the software UNI GRAPHICS module can perform structural analysis, for the UNI GRAPHICS model. In this project, the structural design of a lathe-bed is first conducted, on modeling, and then employed for finite element analysis. It is shown by the result that, measures like finite element analysis can be employed in optimizing design, thereby, avoiding the inherent 
structural defects and disadvantages.

Bed

The bed supports all major components of the lathe. Beds have a large mass, and are built rigidly, usually manufactured from cast iron, as shown in figure 1

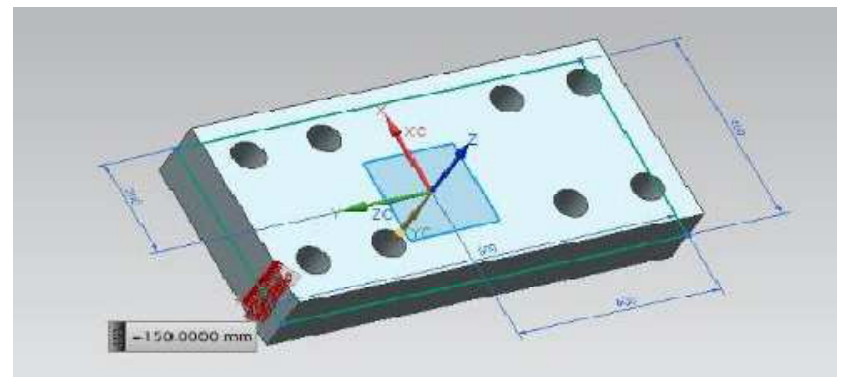

Figure 1: Lathe Machine Bed

\section{Lathe Construction}

There are four fundamental gatherings of segments, that involve the reason for all motor machines. These comprise of the: bed, headstock, tailstock, and the carriage.

The bed is the establishment of the motor machine. The bed is a substantial, tough throwing made to help the working parts of the machine. The size and mass of the bed, give the unbending nature vital for precise designing resilience, required in assembling today. Over the bed are machined ways, which guide and adjust the carriage and tailstock, as they are moving from one end of the machine to the next. The headstock is braced on the bed, at the left-hand end of the machine. The headstock contains the engine, that drives the axle through a progression of riggings. The work piece is mounted to the axle, through methods for a hurl, faceplate, or collet. Since, the headstock contains the engine and drive adapts, the speed or RPM at which the axle pivots, is additionally controlled here. The headstock additionally contains the power, sustain modifications, which are the controls for the rate at which the carriage moves, when the power encourage lever. The carriage gathering moves lengthwise (longitudinally), along the courses between the headstock and the tailstock. The carriage is made out of the cross slide, compound rest, seat, and smock. The seat is an $\mathrm{H}$ molded throwing, mounted over the ways, and backings the cross slide and compound rest. The overskirt is affixed to the seat, and houses the programmed encourage instruments. The cross slide is mounted over the seat, and can be moved either physically or naturally, over the longitudinal pivot (Z-hub) of the shaft. This gives the machines X-hub, which is the breadth of the work piece, it is machined to. The compound rest holds the instrument post, which underpins the cutting device. Mounted over the cross slide, the compound rest can be swiveled to any edge in the even plane. This is helpful, when stopping points and decreases on the work piece.

\section{MODELING AND SIMULATION OF LATHE MACHINE BED}

The major dimensions of the lathe machine bed are as follows

Length $=800 \mathrm{~mm}$

Width $=400 \mathrm{~mm}$

Height $=150 \mathrm{~mm}$ 


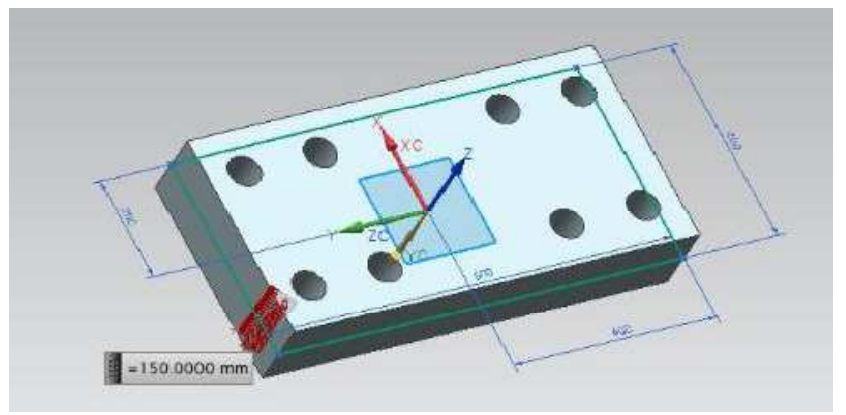

Figure 2: D CAD Model of Lathe Machine Bed (Base Line Design)

Applying Loads and Boundary Conditions

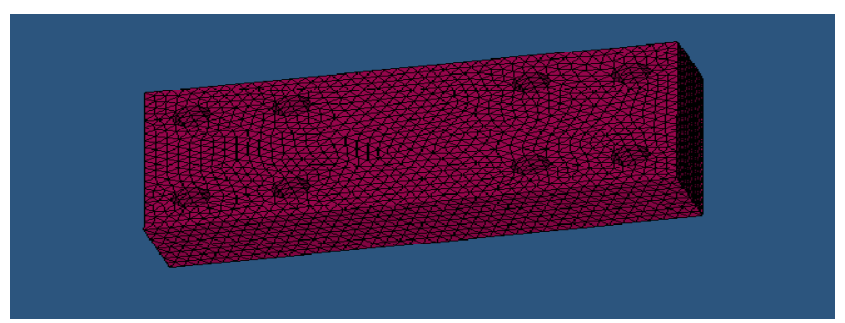

Figure 3: Various Loads Applied on Milling Machine Bed

FINITE ELEMENT ANALYSIS OF MILLING MACHINE BED

Table 1: Material Properties

\begin{tabular}{|c|c|c|c|}
\hline Material properties & Young's modulus & Poisson Ratio & Density \\
\hline Cast Iron & $160 \mathrm{Gpa}$ & 0.3 & $7340 \mathrm{~kg} / \mathrm{m}^{3}$ \\
& & & \\
\hline
\end{tabular}

Applying Boundary Conditions and Loads

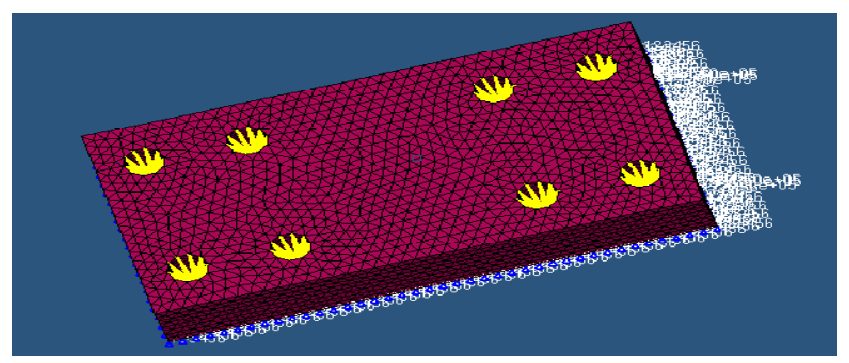

Figure 4: Applying Loads and Boundary Conditions 


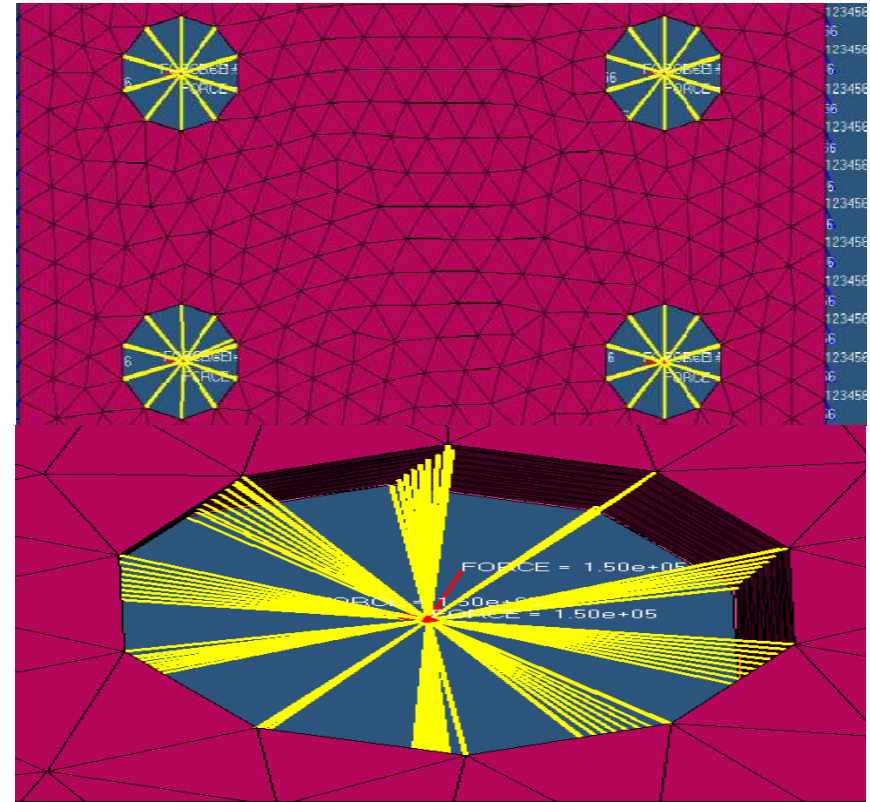

Figure 5: Applying Loads and Rigids at Bolted Location of the Bed

The above figure 5 shows that, rigids and loads are applied at bolted locations of the lathe machine bed. The bottom of the bed is constrained, to the load applied on the top of the lathe bed.

\section{Stastic and Modal Analysis of Bed}

In the present work, the lathe system is modeled and analyzed using radios software.

An analysis, based on the solid element types, tetra mesh is employed. In this system, consider the two types of analysis; one is static analysis and the other is modal analysis.

\section{Static Analysis}

The static analysis is carried out to find maximum stress and maximum displacement, of the lathe bed for giving load condition. On the lathe bed, different loads are acting (static and dynamic loads) before the analysis, by using rigid on the component, and applying constrained or boundary condition. In-bed constrains, or boundary condition is fixed in bolting location.

From the analysis, $150 \mathrm{KN}$ load condition for maximum stress and displacement results, are shown in the below figures.
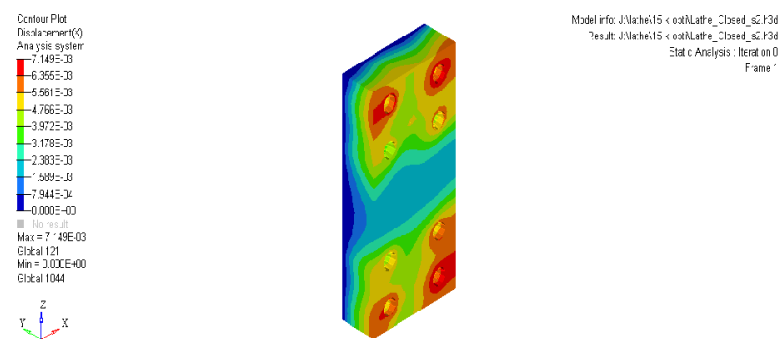

Figure 6: Maximum Displacement along x Direction of the Bed 
The maximum displacement occur at bolted locations, as shown in figure 4 and 5
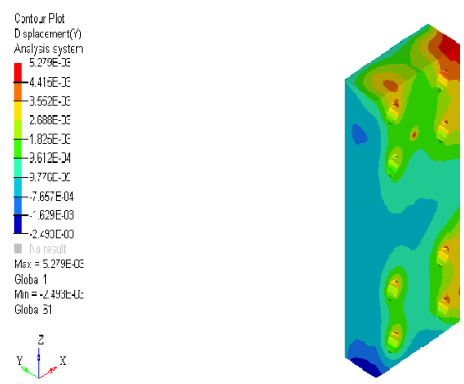

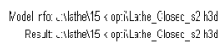

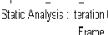

Figure 7: Maximum Displacement along Y Direction of the Bed
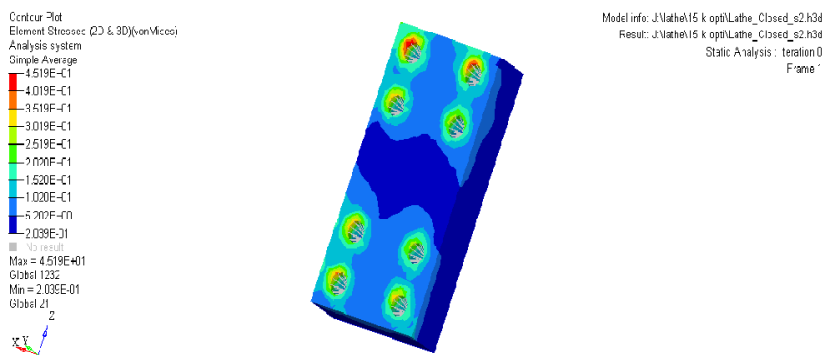

Figure 8: Vonmesis Stress of Lathe Machine Bed

The maximum stress developed in the bed at bolted locations is, as shown in figure 6 . At the center of the bed, minimum stress is developed.

\section{Modal Analysis}

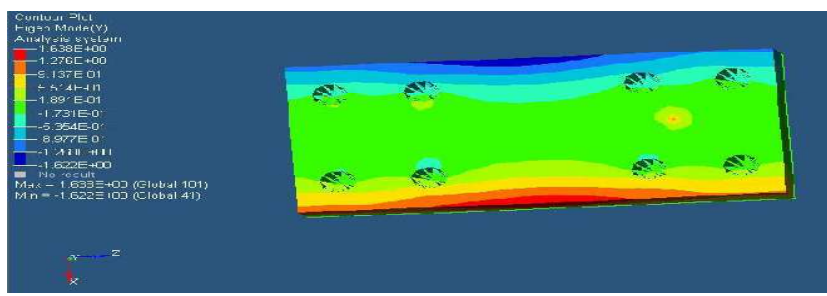

Figure 9: Mode Shape 1 for Lathe Machine Bed

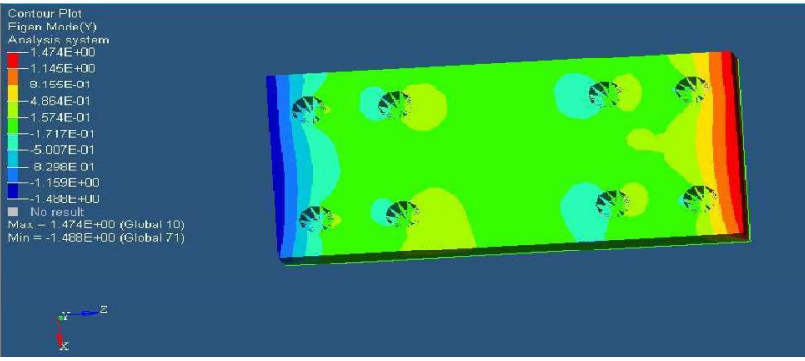

Figure 10: Mode Shape 2 for Lathe Machine Bed 


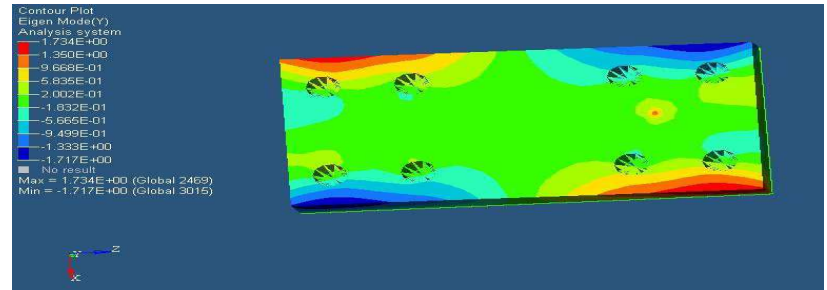

Figure 11: Mode Shape 3 for Lathe Machine Bed

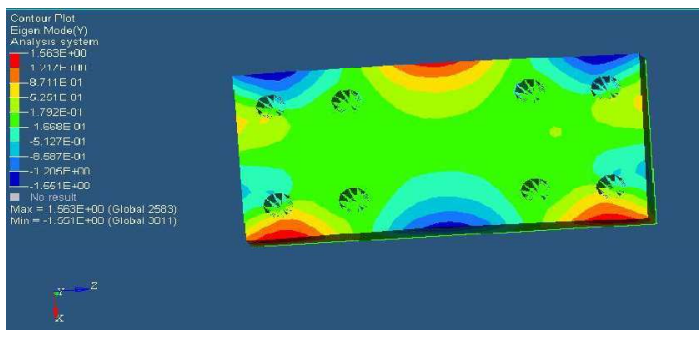

Figure 12: Mode Shape 4 for Lathe Machine Bed

\section{OPTISTRUCT}

Altair OptiStruct is a limited component and multi-body elements programming, for the plan investigate, and streamlining of structures and mechanical frameworks.

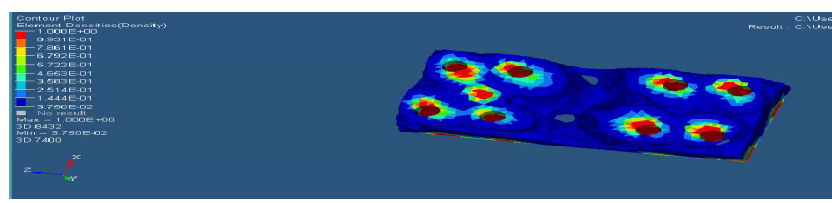

Figure 13: Element Densities of the Optistruct

This is done, to check the areas/ regions, where a structure's mass can be diminished or potentially expelled. This is finished with the assistance of OPTISTRUCT. In this investigation, the model is separated into two zones, in particular outline space and non- plan space. The outline space implies the zone, which is taken into consideration, changes to be made while the non-plan space demonstrates basic locales, which cannot be altered. Reasonable plan factors are to be chosen, by indicating their upper and lower limits and target work is to be decided for either augmentation or minimization.

\section{OPTIMIZED LATHE MACHINE BED}

The size enhancement is done, to check the areas/ranges where a structure's mass can be decreased and additionally expelled. This is finished with the assistance of OPTISTRUCT. As a reduction in weight of lathe bed structures can help in increase of payload capacity, reducing costs, and hence designed structure must be light in weight and should retain their strength and stiffness, throughout the bed.

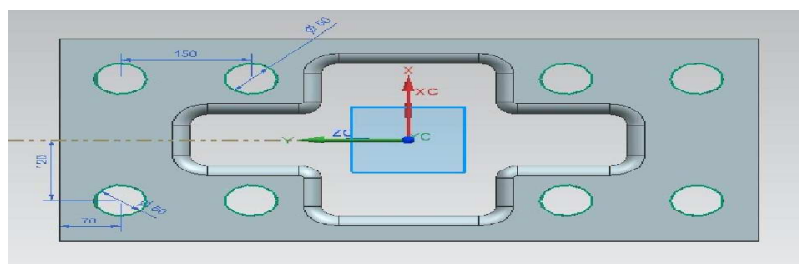

Figure 14: After Optimization Top View of the Model 
The upgraded miscreant needs to expel a few masses, from the first body. At that point, the optimized model need to import the hyper work programming, at that point coinciding was begun to as takes after.

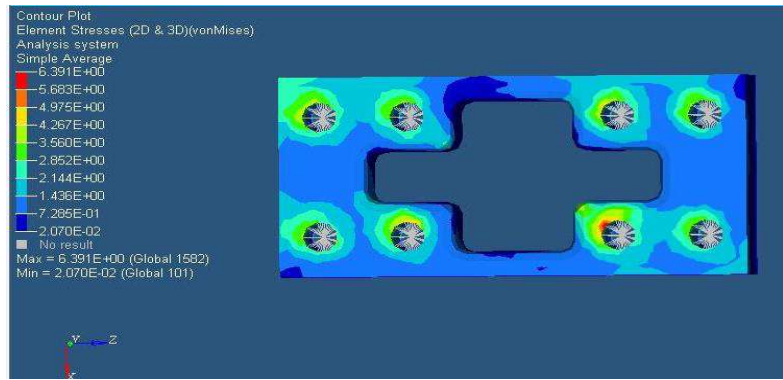

Figure 15: Von Mesis Stress of Optimized Lathe Machine Bed

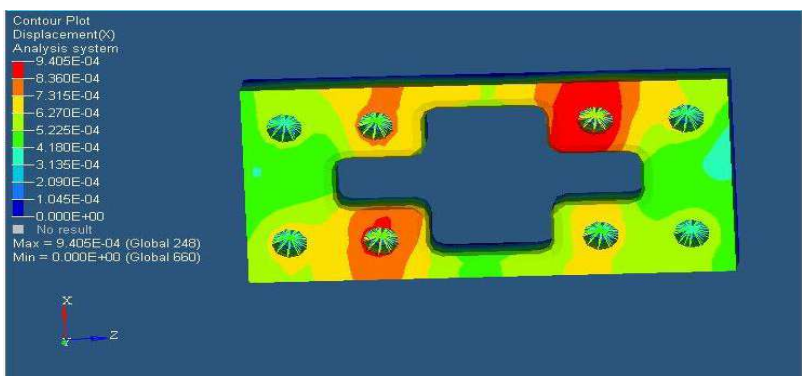

Figure 16: Displacement of Optimized Lathe Machine Bed

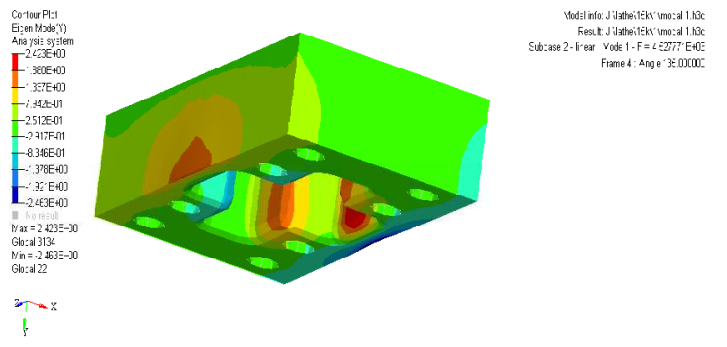

Figure 17: Mode Shape 1 of Optimized Bed

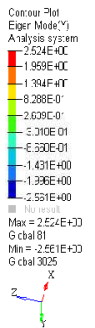

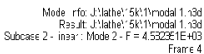

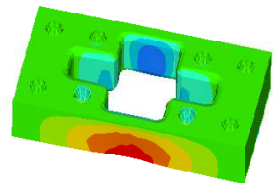

Figure 18: Mode Shape 2 of Optimized Bed 


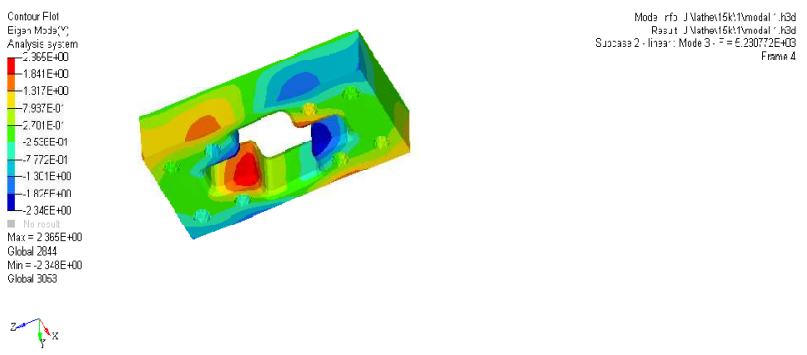

Figure 19: Mode Shape 3 \& 4 of Optimized Bed
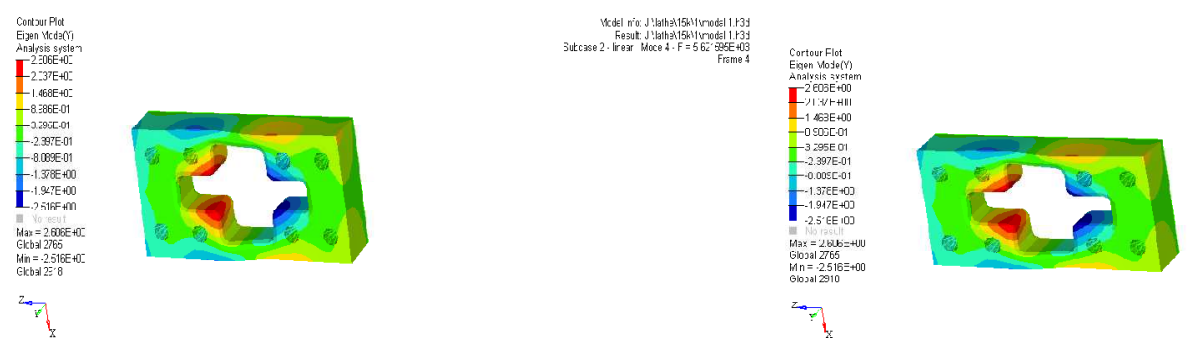

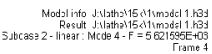

Figure 20

\section{RESULTS \& DISCUSSIONS}

The after effects of static auxiliary examination, modular utilizing ANSYS and the streamlining study utilizing Optristruct, are exhibited. Likewise, the impacts of mass decrease on the static and dynamic execution of the machine bed talks about it, in detail.

Table 2: Displacements of Milling Machine Bed

\begin{tabular}{|l|l|l|}
\hline Material & Initial model $(\mathrm{mm})$ & Optimized model $(\mathrm{mm})$ \\
\hline Cast Iron & 0.00714 & 0.0094 \\
\hline
\end{tabular}

The above table 1, shows the displacement of initial model and optimized model. After the optimized displacement has small increment, this is not affected on the bed. It is watched that, cast press is having greater malleability and thus, having greater removal. As cast iron is having moderate malleability, it is seen to have direct relocation.

Table 3: Vonmesis Stress of Lathe Machine Bed

\begin{tabular}{|c|c|c|}
\hline Material & Initial Model (Mpa) & Optimized Model Mpa) \\
\hline Cast Iron & 49.12 & 63.91 \\
\hline
\end{tabular}

The above table 2 shows, the Vonmesis stress of the initial model is $49.12 \mathrm{~N} / \mathrm{mm} 2$ and optimized model is $63.12 \mathrm{~N} / \mathrm{mm} 2$. The effect of Vonmesis stress is increased and it is in permissible safe limit.

Table 4: Comparison of Weight of Lathe Machine Bed

\begin{tabular}{|l|l|l|}
\hline Material & Initial model $(\mathrm{Kg})$ & Optimized model $(\mathrm{Kg})$ \\
\hline Cast Iron & 753.6 & 712.5 \\
\hline
\end{tabular}


From the above results, the weight optimization of lathe machine bed structure, has been decreased by $41.1 \mathrm{Kg}$, from $753.6 \mathrm{Kg}$ to $712.5 \mathrm{Kg}$ (approximately $1.5 \%$ ), hence, the manufacturing cost also has been reduced.

Following are the modal results, obtained for the bed, which is fixed at the bottom of the bed, and the load is applied on top of the bed.

Table 4: Modal Analysis Results for Cast Iron Bed

\begin{tabular}{|c|c|c|}
\hline Material & Initial model (Hz) & Optimized model (Hz) \\
\hline Mode shape 1 & 4385 & 4527 \\
\hline Mode shape 2 & 4722 & 4882 \\
\hline Mode shape 3 & 5142 & 5230 \\
\hline Mode shape 4 & 5538 & 5621 \\
\hline
\end{tabular}

The natural frequency is increased. For the different mode shapes, the frequencies are obtained for initial and the optimized model is tabulated, in the table 4.

\section{CONCLUSIONS}

The following points are concluded on a lathe machine bed

- The weight optimization of the lathe machine bed structure carried out, shows a decrease in weight by $41.1 \mathrm{Kg}$, that is from initial $753.6 \mathrm{Kg}$ to $712.5 \mathrm{Kg}$ (approximately $1.5 \%$ ).

- Structural analysis of the lathe machine bed carried out shows, the von mises stress, increasing from $49.12 \mathrm{~N} / \mathrm{mm} 2$ to $63.12 \mathrm{~N} / \mathrm{mm} 2$. This increased value of von mises stress, was found to be within the permissible safe limit. The effect of Vonmesis stress, for cast iron was increased and it is in permissible safe limit.

- $\quad$ From the model analysis it was found that, the natural frequency was increased from $5538.92 \mathrm{~Hz}$ to $5621.59 \mathrm{~Hz}$. This increase in the natural frequency, does not affect much on the lathe machine bed.

- From the above outcomes, the given press was chosen a role, as the best material because of low burdens and high normal frequencies, when it is contrasted on different materials.

- The structural analysis will improve the conventional design of the machine structure.

\section{SCOPE FOR FUTURE WORK}

In the present work, static analysis is performed for $150 \mathrm{KN}$ load, for determining stress and displacements for lathe machine bed. Hence, future work can be carried out, for performing the increasing load, to determine stress and displacement for lathe machine bed.

The modal analysis was performed, to determine the mode shapes and natural frequency of the lathe machine bed. Future work can be carried out, for performing transient analysis to determine the time varying displacements.

The optimization was carried out, to reduce the weight of the lathe machine bed, without detoriating structural stiffness. Further, decrease in the lathe machine bed, based on the different structural modifications, and optimization can also be achieved in the future. 


\section{REFERENCES}

1. S. Syath ABUTHAKEER, P.V. MOHANRAM, G. Mohan KUMAR, "Structural redesigning of a cnc lathe bed to improve its static and dynamic characteristics', Tome ix (year 2011).Fascicule3 (ISSN1584-2673).

2. D. Li, Y. Guan, G. Xu and W. Mao, "Optimization Design of Lather-beds Based on FEA”, Proceedings of the 2009 IEEE International Conference on Information and Automation June 22 -25, 2009, Zhuhai/Macau, China.

3. B. Malleswara Swami, K. Sunil Ratna Kumar, "Design and structural analysis of cnc vertical milling machine bed”, Swami et al, International Journal of Advanced Engineering Technology E-ISSN 0976-3945.

4. Jagadish. M. S. and H. V. Ravindra, Monitoring, the Machine Elements in Lathe Using Vibration Signals, Dept. of Mech. Engg. P.E.S.C.E. Mandya. 571401.

5. Hyun Surk Kim KyuYeol Park Dai Gil Lee Pokażwszystkiezasoby, "A study on the epoxy resin concrete for the ultra-precision machine tool bed", Journal of Materials Processing Tech.1995 | 48 | 1-4 | 649-655.

6. Jung Do Suh, Dai Gil Lee, "Design and manufacture of hybrid polymer concrete bed for high-speed CNC milling machine", International Journal of Mechanics and Materials in Design 04/2012; 4(2):113-121. DOI: 10.1007/s10999-007-9033-3.

7. M. Mori (2), H. Mizuguchi, M. Fujishima, Y. Ido, N. Mingkai, K. Konishi, "Design optimization and development of CNC lathe headstock to minimize thermal deformation

8. CIRP”, Annals - Manufacturing Technology 58 (2009), pp. 331-334. 